Original Article

\title{
The L-arginine/nitric oxide pathway is impaired in overweight/ obese pregnant women
}

\author{
Elisabetta Petrella, Lucrezia Pignatti, Isabella Neri, Fabio Facchinetti* \\ Mother-Infant Department, University of Modena and Reggio Emilia, Modena, Italy
}

\section{A R T I C L E I N F O}

\section{Article history:}

Received 27 November 2013

Received in revised form 17 January 2014

Accepted 17 January 2014

Available online 3 February 2014

\section{Keywords:}

L-arginine

Endothelial function

Insulin

Pregnancy

\begin{abstract}
A B S T R A C T
Objective: To evaluate the L-arginine/NO system and its role in insulin signaling and endothelial function during the pregnancy of women of different BMI categories.

Study design: Twelve women with BMI $\geqslant 25$ were compared with 10 normal-weight women in a fasting condition after the infusion of L-arginine ( $20 \mathrm{~g}$ in $3 \mathrm{~h}$ ) and after the evaluation of the flow-mediated vasodilation (FMD) of the brachial artery between the 9th-12th and 24th-27th weeks. Blood samples for insulin and nitrite/nitrate (NOx) were collected at baseline and after 1, 2 and $3 \mathrm{~h}$ after initiating the infusion.

Results: In both trimesters, the baseline NOx levels were similar among groups. In the 1st trimester of the lean women, there was a NOx increase in response to L-Arg (AUC: 1328; 3, 3173), which had increased by the 2nd trimester (AUC: 3884; 1905, 7686); in overweight/ obese women, no responses to L-Arg were found in the 1st or 2nd trimesters. In the 1st trimester, the insulin levels were significantly reduced in both groups after L-Arg infusion. Although the insulin levels in all BMI categories were higher in the 2nd trimester, such levels during weeks 24-27 were suppressed only in normal-weight women after L-Arg infusion. The FMD was higher during both trimesters in the lean controls and was impaired in the overweight/obese subjects.

Conclusions: NO availability is impaired in overweight/obese women during pregnancy, which affects endothelial functioning and interferes with insulin regulation. These mechanisms could be involved in the development of hypertensive disorders and glucose intolerance in this population.
\end{abstract}

(c) 2014 International Society for the Study of Hypertension in Pregnancy Published by Elsevier B.V. All rights reserved.

\section{Introduction}

Pregnancy is physiologically characterized by hyperinsulinemia and insulin resistance (IR) [1,2]. During the third trimester, insulin sensitivity is reduced by up to $50-70 \%$

Abbreviations: NOx, nitrite/nitrate; mm, millimeters; AUC, area under the curve; IR, insulin resistance; BMI, body mass index; HOMA index, homeostasis model assessment index.

* Corresponding author. Address: Policlinico Hospital, University of Modena and Reggio-Emilia, Mother-Infant Department, Via del Pozzo 71, 41124 Modena, Italy. Tel.: +39 0594222512.

E-mail address: fabio.facchinetti@unimore.it (F. Facchinetti). compared with pre-pregnancy levels [3]. IR is a common condition in overweight/obese subjects because of the endocrine activity of adipokines produced by visceral adipose tissue. The increased visceral adipose tissue is known to regulate glucose homeostasis, energy metabolism, the immune system, coagulation and blood pressure [4]. In particular, tumor necrosis factor- $\alpha$ (TNF- $\alpha$ ) and non-esterified fatty acids (NEFA) appear to have a leading role in insulin resistance development, and concentrations of TNF- $\alpha$ and NEFA are both increased in the obese population [4-6].

In addition to glucose metabolism, insulin is implicated in the regulation of endothelial function and acts through 
2 different pathways of signal transduction: the phosphatidylinositol (PI) 3-kinase-dependent pathway and the mitogen-activated protein (MAP) kinase pathway. The activation of PI 3-kinase is a necessary condition for the insulin-stimulated production of nitric oxide (NO) by the endothelium and for GLUT4 translocation, which allows glucose uptake in the skeletal muscle [7]. This pathway is involved in physiological intracellular insulin signaling transmission. Therefore, insulin signaling in the vascular endothelium results in increased blood flow and contributes to glucose disposal, suggesting a possible mechanism that couples glucose metabolism with hemodynamic mechanisms [7,8]. Moreover, the increased blood flow itself leads to a greater inflow of insulin to the skeletal muscle, which further increases glucose uptake. Moreover, inhibiting NO production precipitates a parallel decline in blood flow and a decrease in glucose utilization of approximately 40\% [9].

During IR, insulin induces extracellular signal-regulated kinase (ERk1/ERk2) and, as a consequence, mitogen-activated protein kinase, which leads to endothelin-1 production and atherosclerosis onset. However, the transmission of intracellular signaling is impaired.

In the endothelium, NO is produced by endothelial NO synthase enzyme (eNOS) from the amino acid L-arginine, in response to either shear stress or hormonal stimuli (i.e., insulin), inducing endothelial-dependent vasodilation [10].

Hyperinsulinemia, related to IR and resultant from increased glucose levels, enhances the production of reactive oxygen species (ROS) and, thus, oxidative stress and endothelial dysfunction [10-13]. Adipokines (particularly TNF- $\alpha$ ) could activate several kinases, which reduce PI 3-kinase function, thereby decreasing glucose uptake and eNOS function [7].

According to previously exposed mechanisms, obesity negatively affects endothelial function. It has been demonstrated that endothelial-dependent vasodilation is reduced by $40-50 \%$ in obese subjects (with or without diabetes) compared with normal-weight subjects [14]. In the same study, increased body mass index (BMI) categories correspond to a progressive decrease of endothelial-dependent vasodilation [14].

A previous study performed by our group demonstrated that an acute L-arginine ( $\mathrm{L}-\mathrm{Arg}$ ) infusion was able to reveal a NOS impairment in pre-eclamptic (PE) women, as demonstrated by significantly lower serum L-citrulline production with respect to normotensive controls [15]. The serum NO levels were increased in the controls but not in the PE women, which supports the hypothesis that preeclampsia is characterized by a dysfunction of the L-Arg/NO pathway [15]. Moreover, we have also demonstrated that an acute L-Arg infusion was able to induce a vasodilation in placenta-related fetal growth restriction, improving uterine artery blood flow velocimetry [16].

The L-Arg/NO pathway is also involved in glucose metabolism. Recent studies demonstrate that an alteration in NO availability appears to be involved in the pathogenesis of type 2 diabetes mellitus (T2 DM) [7,17].

Considering that the prevalence of obesity is increasing in the general population and that the top BMI categories in pregnant women are also increasing, we aim to evaluate the L-Arg/NO regulatory system in lean and obese pregnant women for both insulin signaling and endothelial function.

\section{Methods}

Subjects

The study was approved by the local ethics committee. After signing an informed consent form, 22 healthy pregnant women volunteered for the study.

The inclusion criteria were Caucasian ethnicity, age 1840 years, single pregnancy, and gestational age between 9 and 12 weeks at the time of recruitment.

Exclusion criteria were concomitant disorders (chronic hypertension or pre-gestational type 1 or 2 diabetes mellitus) or previously complicated pregnancies.

Blood pressure, height and weight were measured, and BMI was calculated. Morbidly obese subjects were excluded. The 12 overweight/obese women (BMI $\geqslant 25$ $\mathrm{kg} / \mathrm{m}^{2}$ ) were compared with 10 normal-weight women (BMI range $18-25 \mathrm{~kg} / \mathrm{m}^{2}$ ).

All volunteers were enrolled at the Obstetric Unit of Policlinico Hospital, University of Modena and Reggio-Emilia.

\section{Study design}

The enrolled subjects underwent both L-Arg infusion and evaluation of the endothelial-dependent flow-mediated vasodilation (FMD) of the brachial artery twice during pregnancy. The tests were performed between the 9th and 12 th, as well as between the 24th and 27th weeks, respectively, within 2 days of each other.

In the 1 st trimester and within the 12th week, the fasting glucose and insulin levels were measured to evaluate the homeostasis model assessment (HOMA) index. The HOMA index was calculated as follows: [(fasting glucose $\mathrm{mg} / \mathrm{dl}) \times($ fasting insulin $\mathrm{mUI} / \mathrm{L})] / 405$. A HOMA index higher than 2.5 is suggestive of IR.

In a fasting condition between 8 and 9 A.M., the L-Arg ( $20 \mathrm{~g}$ in $500 \mathrm{ml}$ physiological solution) was continuously infused for $3 \mathrm{~h}$. Blood samples for insulin and nitrite/ nitrate (NOx) were collected at baseline and after 1, 2 and $3 \mathrm{~h}$ after initiating the infusion.

\section{Methods}

The serum NOx concentration was obtained after a reduction of nitrates to nitrites with cadmium. The nitrite assay was performed using the colorimetric method based on a Griess reaction, and the results are expressed in $\mu \mathrm{M} / \mathrm{L}$. The quantitative determination of the plasma insulin levels was obtained using the ELISA method, and the concentrations are expressed in $\mu \mathrm{IU} / \mathrm{ml}$.

The ultrasound assessment of FMD was performed to measure the percent change of the brachial artery diameter in response to increased blood flow shear stress, as previously described by Coretti et al. [18]. The measurements were performed in a dark, quiet ->and temperature-controlled room ->in the morning after at least $12 \mathrm{~h}$ of fasting. The subjects did not exercise and did not ingest substances 
such as caffeine or high-fat foods and did not use tobacco for at least $12 \mathrm{~h}$ prior to the measurements. The subjects were asked to rest for at least $10 \mathrm{~min}$ (min) prior to the FMD measurements. The brachial artery diameter was imaged using a $7.5 \mathrm{MHz}$ linear transducer ultrasound system (LOGIQ 3, GE Medical Systems, Milwaukee, WI, USA). After the baseline measurements were recorded, a blood pressure cuff was inflated until reaching occlusive pressure on the most proximal portion of the forearm for $5 \mathrm{~min}$ to induce reactive hyperemia. Both the measurements in millimeters and as percent changes of brachial artery diameter were calculated at 1 and $5 \mathrm{~min}$ after the cuff release. To calculate the flow-mediated dilation, the percent diameter changes were determined as follows: (diameter after reactive hyperemia-baseline diameter)/baseline diameter $\times 100$.

\section{Statistical analysis}

Data were recorded to a database and analyzed using SPSS ${ }^{\circledR}$ Statistics version 19. According to the distribution, the Mann-Whitney U-test was used. The Wilcoxon test was applied within the experimental group. To compare the insulin and NOx responses to infusion, the area under the curve (AUC) was calculated using the trapezoidal rule and by subtracting the baseline values.

The values are expressed as the means \pm standard deviation, the median and interquartile range or the number with the percentage sign (\%) in brackets as appropriate.

A $p$ value of less than 0.05 was the threshold for statistical significance.

\section{Results}

The clinical features of the women included in the study are described in Table 1. At enrollment, both the maternal age $(25.6 \pm 4.5$ vs. $32.1 \pm 5.4$ years $)$ and BMI $(21.7 \pm 2.2$ vs. $32.2 \pm 6.2 \mathrm{~kg} / \mathrm{m}^{2}$ ) were significantly higher in the overweight/obese than the normal-weight women $(p<0.001)$. According to the HOMA index, 7 overweight/obese pregnant patients and just 1 normal-weight woman were found to be resistant to insulin, although this difference

Table 1

Clinical features of women stratified for BMI categories.

\begin{tabular}{|c|c|c|c|}
\hline & $\begin{array}{l}\text { Normal- } \\
\text { weight }\end{array}$ & $\begin{array}{l}\text { Overweight/ } \\
\text { obese }\end{array}$ & $p$ Value \\
\hline Serum glucose levels & $\begin{array}{l}78.4 \pm 5.3^{a} \\
(70-84)\end{array}$ & $\begin{array}{l}82.8 \pm 9.3 \\
(71-101)\end{array}$ & NS \\
\hline Serum insulin levels & $\begin{array}{l}8.0 \pm 5.1 \\
(2.8-19.1)\end{array}$ & $\begin{array}{l}17.6 \pm 16.5 \\
(6.5-74.0)\end{array}$ & $p=0.008$ \\
\hline HOMA index & $\begin{array}{l}1.7 \pm 1.0 \\
(0.5-4.0)\end{array}$ & $\begin{array}{l}3.8 \pm 4.2 \\
(1.3-18.4)\end{array}$ & NS \\
\hline HOMA > 2.5 & $1(10.0 \%)^{b}$ & $7(58.3 \%)$ & NS \\
\hline $\begin{array}{l}\text { Systolic blood pressure } \\
\quad(\mathrm{mmHg})\end{array}$ & $\begin{array}{l}104.1 \pm 10.4 \\
(85.0- \\
115.0)\end{array}$ & $\begin{array}{l}121.6 \pm 15.1 \\
(95.0-137.0)\end{array}$ & 0.004 \\
\hline $\begin{array}{l}\text { Diastolic blood pressure } \\
\quad(\mathrm{mmHg})\end{array}$ & $\begin{array}{l}61.8 \pm 6.0 \\
(53.0-68.0)\end{array}$ & $\begin{array}{l}73.3 \pm 9.6 \\
(55.0-85.0)\end{array}$ & 0.002 \\
\hline
\end{tabular}

\footnotetext{
a Mean \pm SD with range in brackets.
}

b $\mathrm{N}$ with \% in brackets. was not statistically significant. At both trimesters, any symptom (i.e., vomiting, cephalgia, etc.) during or after the L-Arg infusion was observed in our study population.

In the 1st (normal-weight: $22.2 \pm 13.9 \mu \mathrm{M} / \mathrm{L}$, overweight/obese: $33.1 \pm 14.9 \mu \mathrm{M} / \mathrm{L}$ ) and 2 nd trimester (normal-weight: $20.0 \pm 11.6 \mu \mathrm{M} / \mathrm{L}$, overweight/obese: $29.3 \pm$ $15.8 \mu \mathrm{M} / \mathrm{L}$ ) evaluations, the baseline NOx levels were similar among the 2 groups. In the normal-weight women in the 1st trimester, there was a NOx increase in response to the L-Arg infusion (AUC: 1328; 3, 3173), which had further increased by the 2nd trimester (AUC: 3884; 1905, 7686). In the overweight/obese women, no responses to L-Arg occurred in the 1st or 2nd trimester (Fig. 1).

During the 1 st trimester, the fasting insulin levels were significantly higher in the overweight/obese group $(17.6 \pm 12.5 \mu \mathrm{IU} / \mathrm{ml})$ than in the control group $(8.0 \pm 5.1 \mu \mathrm{IU} / \mathrm{ml} ; p<0.01)$; however, in the 2 nd trimester, the fasting insulin levels became similar (overweight/obese: $17.3 \pm 8.2 \mu \mathrm{IU} / \mathrm{ml}$; normal-weight: $18.0 \pm 11.4 \mu \mathrm{IU} /$ $\mathrm{ml}$ ). In the 1 st trimester, the insulin levels were significantly reduced after $3 \mathrm{~h}$ of $\mathrm{L}$-Arg infusion in both groups $(p=0.05)$ (Fig. 2). However, in the 2nd trimester, the insulin levels were significantly lower only in the normalweight group (AUC: $-229 ;-515,-73$ ) and not in the overweight/obese women (AUC: $-86 ;-594,165 ; p=0.02$ ).

The brachial artery dilation response to increased blood flow shear stress (both expressed in millimeters and as percent changes of the brachial artery diameter after the cuff release) in lean women was higher in the 1st than the 2 nd trimester (Table 2). In the overweight/obese women, no vasodilatory responses were observed in the 1 st or 2nd trimester.

\section{Discussion}

Human pregnancy is associated with dramatic changes in the maternal cardiovascular system, leading to a decrease in blood pressure as a consequence of reduced peripheral vascular resistances [19]. NO plays a pivotal role in this context [20-23]. The data of our study support such an observation and demonstrate an impairment of NO availability, namely in the 2nd trimester, in overweight/obese women. Consequently, both endothelial-dependent vasodilation and insulin regulation appear to be compromised.

Endothelial dysfunction during pregnancy is involved in the pathophysiology of several adverse conditions such as preeclampsia [24-26], which is precipitated by the inability to release NO [27] and leads to a worsening of FMD $[28,29]$. However, PE and gestational hypertension have an increased prevalence in obese women and result in more preterm deliveries and significant neonatal morbidity and mortality [30]. Our findings suggest that such pregnancy complications could be related to impaired NO release. Whether such impairment is a consequence of preeclampsia or, alternatively, whether it plays a causal role in the onset of this condition remains to be demonstrated.

Previous studies have demonstrated that NO is produced in the endothelium of placental vessels by eNOS [31]. Because there is no innervation of such vessels, vasodilation has been thought to occur primarily through locally produced vasodilators [32-34]. Thus, the most 

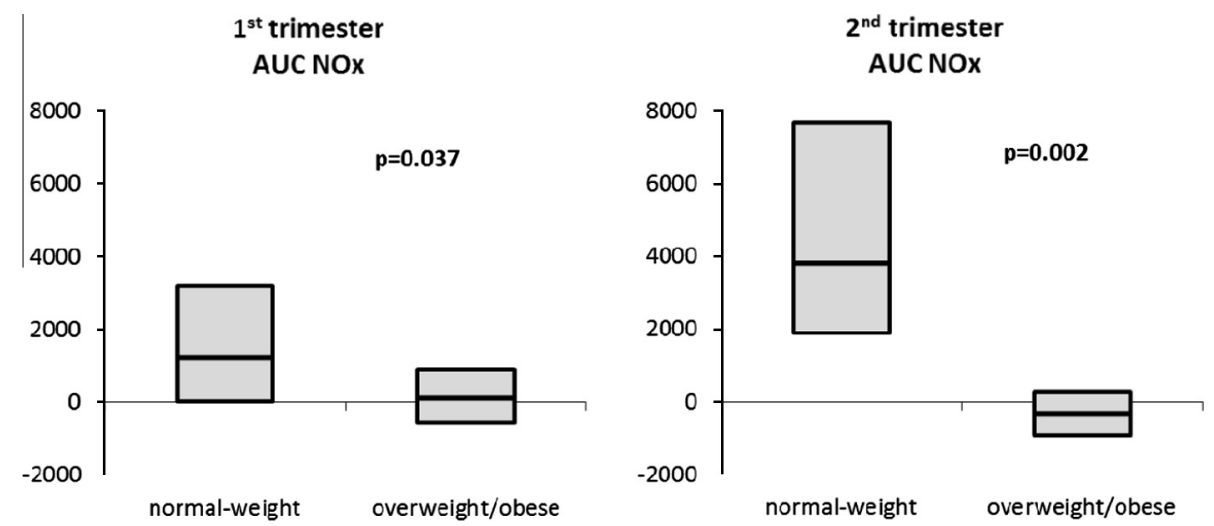

Fig. 1. NOx production in response to L-Arg infusion. AUC: area under the curve.

L-Arg infusion at $1^{\text {st }}$ trimester

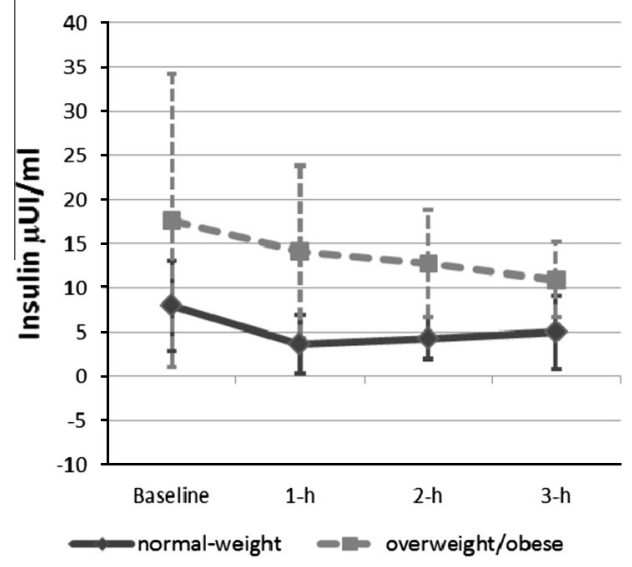

L-Arg infusion at $2^{\text {nd }}$ trimester

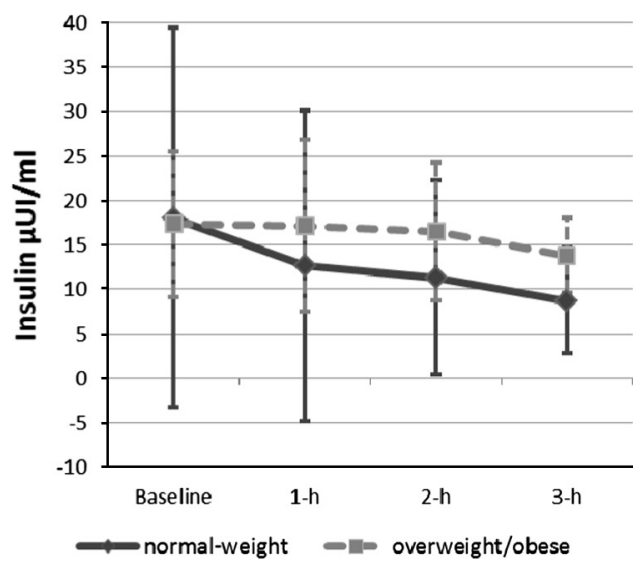

Fig. 2. Insulin levels in response to L-Arg infusion.

Table 2

Brachial artery diameter changes in response to increased blood flow shear stress after cuff release.

\begin{tabular}{|c|c|c|c|c|}
\hline & \multicolumn{2}{|l|}{ 1st Trimester } & \multicolumn{2}{|l|}{ 2nd Trimester } \\
\hline & Normal-weight & Overweight/obese & Normal-weight & Overweight/obese \\
\hline Baseline & $3.6 \pm 0.7^{\mathrm{a}}$ & $3.7 \pm 0.7$ & $4.0 \pm 0.2$ & $3.7 \pm 0.8$ \\
\hline 1st Minute & $4.4 \pm 0.9$ & $4.4 \pm 0.9$ & $5.1 \pm 0.7$ & $4.0 \pm 0.9$ \\
\hline (\% Change) & $(23.4 \pm 12.1)^{\mathrm{b}}$ & $(16.9 \pm 12.3)$ & $(26.5 \pm 10.9)$ & $(7.92 \pm 9.6)$ \\
\hline 5th Minute & $6.0 \pm 1.3$ & $4.6 \pm 0.7$ & $5.4 \pm 0.5$ & $4.3 \pm 1.0$ \\
\hline (\% Change) & $(67.4 \pm 32.9)$ & $(24.7 \pm 16.9)^{*}$ & $(32.18 \pm 6.7)$ & $(16.7 \pm 13.3)^{*}$ \\
\hline
\end{tabular}

${ }^{\text {a }}$ Means \pm SD diameter changes in millimeters $(\mathrm{mm})$.

${ }^{\mathrm{b}}$ Means $\pm \mathrm{SD} \%$ change over baseline.

${ }^{*} p<0.05$ in respect to normal weight.

important fetal placental vasodilator is NO because it is not only constitutively produced but is also dramatically stimulated by increases in shear stress (which occurs with increased blood flow) [20-23]. However, another factor that should be taken into account is the status of chronic oxidative stress, which has been demonstrated in obese women through the exposure of endothelium to adipokine activity [10-13]. Inflammatory cytokines, particularly TNF$\alpha$, decrease the expression of mitochondrial oxidative phosphorylation genes, which increases oxidative cellular stress and the accumulation of reactive oxygen species (ROS) [35]. Therefore, we cannot exclude that the low detection of NOx in obese/overweight women during the course of pregnancy is a consequence of a reduced production or faster inactivation.

Moreover, capillary recruitment and blood flow enhance the delivery of glucose in skeletal muscle, in which mass action promotes glucose transport. Elevations in 
blood flow also increase the delivery of insulin to skeletal muscle, where insulin directly promotes glucose uptake through stimulating the translocation of GLUT4 [7].

Our data are in agreement with previous findings and demonstrate that women with a BMI $\geqslant 25 \mathrm{~kg} / \mathrm{m}^{2}$ presented higher insulin levels than normal-weight women as early as the 1st trimester [4-6]. Moreover, as expected, lean women increase their baseline insulin in the 2nd trimester to compensate for the physiological rise of insulin resistance; these women implement the positive glucose gradient from the maternal to fetal side for proper fetal growth $[1,2]$.

After the L-Arg infusion at weeks 24-27, the insulin levels appeared to be reduced only in the normal-weight women. This finding could be explained by the lack of NO availability in overweight/obese subjects, highlighting the role of $\mathrm{NO}$ in intermediate metabolism.

However, NO is also involved in insulin regulation, as previously demonstrated [36]. An alteration in NO availability appears to be implicated in the pathogenesis of type 2 diabetes mellitus $[7,17,37]$. In islet $\beta$-cells, pro-inflammatory cytokines (largely expressed by visceral adipose tissue) acutely activate the expression of the Nos2 gene (that encodes inducible nitric oxide synthase (iNOS)), which ultimately impairs insulin release [36]. This phenomenon could explain our findings: in the 2nd trimester, the insulin levels appear to be reduced only in the normalweight women.

In summary, these data demonstrate that NO availability is impaired in overweight/obese women compared with lean controls during the course of pregnancy. The reduced NO availability affects endothelial-dependent vasodilation and interferes with insulin regulation. These mechanisms could be involved in the increased risk of developing hypertensive disorders and glucose intolerance in the overweight/obese population.

\section{Author contributions}

L. Pignatti and E. Petrella performed the L-Arg infusion and evaluated endothelial functioning. They also contributed to writing the paper and collecting data.

I. Neri and F. Facchinetti designed the research and contributed to writing the paper and collecting data.

Each author contributed to collecting data, performing the data analysis and interpreting the results.

\section{Ethics Statement}

The study has been approved by the local ethics committee.

\section{Funding}

The authors have no support or funding to report.

\section{Competing interests}

There is no conflict of interest.

\section{References}

[1] Hadden DR, McLaughlin C. Normal and abnormal maternal metabolism during pregnancy. Semin Fetal Neonatal Med 2009;14:66-71.

[2] Mills JL, Jovanovic L, Knopp R, Aarons J, Conley M, Park E, et al Physiological reduction in fasting plasma glucose concentration in the first trimester of normal pregnancy: the diabetes in early pregnancy study. Metabolism 1998;47:1140-4.

[3] Catalano PM, Tyzbir ED, Roman NM, Amini SB, Sims EA. Longitudinal changes in insulin release and insulin resistance in nonobese pregnant women. Am J Obstet Gynecol 1991;165:1667-72.

[4] Wajchenberg BL. Subcutaneous and visceral adipose tissue: their relation to the metabolic syndrome. Endocr Rev 2000;21:697-738.

[5] Kershaw EE, Flier JS. Adipose tissue as an endocrine organ. J Clin Endocrinol Metab 2004;89:2548-56.

[6] Rosen ED, Spiegelman BM. Adipocytes as regulators of energy balance and glucose homeostasis. Nature 2006;444:847-53.

[7] Kim JA, Montagnani M, Koh KK, Quon MJ. Reciprocal relationships between insulin resistance and endothelial dysfunction: molecular and pathophysiological mechanisms. Circulation 2006;113:1888-904.

[8] Zeng G, Nystrom FH, Ravichandran LV, Cong LN, Kirby M, Mostowsk $\mathrm{H}$, et al. Roles for insulin receptor, PI3-kinase, and Akt in insulinsignaling pathways related to production of nitric oxide in human vascular endothelial cells. Circulation 2000;101:1539-45.

[9] Vincent MA, Barrett EJ, Lindner JR, Clark MG, Rattigan S. Inhibiting NOS blocks microvascular recruitment and blunts muscle glucose uptake in response to insulin. Am J Physiol Endocrinol Metab 2003;286:E123-9.

[10] Pagliaro P. Differential biological effects of products of nitric oxide (NO) synthase: it is not enough to say NO. Life Sci 2003;73:2137-49.

[11] Arcaro G, Cretti A, Balzano S, Lechi A, Muggeo M, Bonora E, et al. Insulin causes endothelial dysfunction in humans: sites and mechanisms. Circulation 2002;105:576-82.

[12] Heitzer T, Krohn K, Albers S, Meinertz T. Tetrahydrobiopterin improves endothelium-dependent vasodilation by increasing nitric oxide activity in patients with Type II diabetes mellitus. Diabetologia 2000;43:1435-8

[13] Deanfield JE, Halcox JP, Rabelink TJ. Endothelial function and dysfunction: testing and clinical relevance. Circulation 2007;115:1285-95.

[14] Steinberg HO, Chaker H, Leaming R, Johnson A, Brechtel G, Baron AD. Obesity/insulin resistance is associated with endothelial dysfunction. Implications for the syndrome of insulin resistance. Clin Invest 1996;97:2601-10.

[15] Facchinetti F, Longo M, Piccinini F, Neri I, Volpe A. L-arginine infusion reduces blood pressure in preeclampti c women through nitric oxide release. J Soc Gynecol Investig 1999;6:202-7.

[16] Neri I, Mazza V, Galassi MC, Volpe A, Facchinetti F. Effects of Larginine on utero-placental circulation in growth-retarded fetuses. Acta Obstet Gynecol Scand 1996;75:208-12.

[17] Rossi R, Cioni E, Nuzzo A, Origliani G, Modena MG. Endothelialdependent vasodilation and incidence of type 2 diabetes in a population of healthy postmenopausal women. Diabetes Care 2005;28:702-7.

[18] Corretti MC, Anderson TJ, Benjamin EJ, Celermajer D, Charbonneau F, Creager MA, et al. International brachial artery reactivity task force, guidelines for the ultrasound assessment of endothelial-dependent flow-mediated vasodilation of the brachial artery: a report of the international brachial artery reactivity task force. J Am Coll Cardio 2002;39:257-65.

[19] Poston L. Maternal vascular function in pregnancy. J Hum Hypertens 1996;10:391-4.

[20] Kuchan MJ, Frangos JA. Role of calcium and calmodulin in flowinduced nitric oxide production in endothelial cells. Am J Physiol 1994;266:C628-36.

[21] Li Y, Zheng J, Bird IM, Magness RR. Effects of pulsatile shear stress on nitric oxide production and endothelial cell nitric oxide synthase expression by ovine fetoplacental artery endothelial cells. Biol Reprod 2003;69:1053-9.

[22] Li Y, Zheng J, Bird IM, Magness RR. Mechanisms of shear stressinduced endothelial nitric-oxide synthase phosphorylation and expression in ovine fetoplacental artery endothelial cells. Biol Reprod 2004;70:785-96.

[23] Li Y, Zheng J, Bird IM, Magness RR. Effects of pulsatile shear stress on signaling mechanisms controlling nitric oxide production, endothelial nitric oxide synthase phosphorylation, and expression in ovine fetoplacental artery endothelial cells. Endothelium 2005;12:21-39. 
[24] Roberts JM, Redman CWG. Pre-eclampsia: more than pregnancyinduced hypertension. Lancet 1993;341:1447-51.

[25] McCarthy AI, Woolfson RG, Raju SK, Poston I. Abnormal endothelial function of resistance arteries from woman with pre-eclampsia. Am J Obstet Gynecol 1993;168:1323-30.

[26] Sladek SM, Magness RR, Conrad KP. Nitric oxide and pregnancy. Am J Physiol 1997;272:441-63.

[27] Fyrchott R, Zawadzki D. The obligatory role of endothelial cells in the relaxation of arterial smooth muscle by acetylcholine. Nature 1980;288:373-6.

[28] Meredith IT, Currie KE, Anderson TJ, Roddy MA, Ganz P, Creager MA. Postischemic vasodilation in human forearm is dependent on endothelium-derived nitric oxide. Am J Physiol 1996;270:H1435-40.

[29] Ioannides R, Haefeli WE, Linder L, Richard V, Bakkali EH, Thuillez C, et al. Nitric oxide is responsible for flow-dependent dilatation of human peripheral conduit arteries in vivo. Circulation 1995;91:1314-9.

[30] Leddy MA, Power ML, Schulkin J. The impact of maternal obesity on maternal and fetal health. Rev Obstet Gynecol 2008;1:170-8.

[31] Myatt L, Eis AL, Brockman DE, Greer IA, Lyall F. Endothelial nitric oxide synthase in placental villous tissue from normal, pre- eclamptic and intrauterine growth restricted pregnancies. Hum Reprod 1997;12:167-72.

[32] Fox SB, Khong TY. Lack of innervation of human umbilical cord. An immunohistological and histochemical study. Placenta 1990;11:59-62.

[33] Myatt L. Control of vascular resistance in the human placenta. Placenta 1992;13:329-41.

[34] Zheng J, Li Y, Weiss AR, Bird IM, Magness RR. Expression of endothelial and inducible nitric oxide synthases and nitric oxide production in ovine placental and uterine tissues during late pregnancy. Placenta 2000;21:516-24.

[35] Gallagher EJ, Leroith D, Karnieli E. Insulin resistance in obesity as the underlying cause for the metabolic syndrome. Mt Sinai J Med 2010;77:511-23.

[36] Nishiki Y, Adewola A, Hatanaka M, Templin AT, Maier B, Mirmira RG. Translational control of inducible nitric oxide synthase by p38 MAPK in islet $\beta$-cells. Mol Endocrinol 2013;27:336-49.

[37] Perticone F, Maio R, Sciacqua A, Andreozzi F, Iemma G, Perticone M, et al. Endothelial dysfunction and C-reactive protein are risk factors for diabetes in essential hypertension. Diabetes 2008;57:167-71. 